\title{
BMJ Open Socioeconomic status and prevalence of chronic non-communicable diseases in Chinese women: a structural equation modelling approach
}

\author{
Hui Yin, ${ }^{1}$ Qunhong Wu, ${ }^{2}$ Yu Cui, ${ }^{2}$ Yanhua Hao, ${ }^{2}$ Chaojie Liu, ${ }^{3}$ Ye Li, ${ }^{2}$ Libo Liang, ${ }^{2}$ \\ Limin Wang, ${ }^{1}$ Yuchun Tao ${ }^{1}$
}

To cite: Yin $\mathrm{H}$, Wu Q, Cui Y, et al. Socioeconomic status and prevalence of chronic non-communicable diseases in Chinese women: a structural equation modelling approach. BMJ Open 2017;7:e014402. doi:10.1136/ bmjopen-2016-014402

\section{- Prepublication history and} additional material for this paper are available online. To view these files please visit the journal online (http://dx.doi. org/10.1136/bmjopen-2016014402).

$\mathrm{HY}$ and $\mathrm{YC}$ contributed equally.

QW and YC are co-first authors.

Received 21 September 2016 Revised 13 March 2017 Accepted 29 March 2017

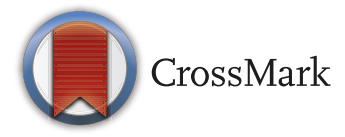

${ }^{1}$ Department of Health Education, School of Public Health, Harbin Medical University, Harbin, People's Republic of China

${ }^{2}$ Department of Social Medicine, School of Public Health, Harbin Medical University, Harbin, People's Republic of China ${ }^{3}$ School of Psychology and Public Health, La Trobe University, Melbourne, Australia

Correspondence to Professor Qunhong Wu; wuqunhong@163.com and Professor Yanhua Hao; hyhyjw@126.com

\section{ABSTRACT}

Objective To investigate the role of socioeconomic status (SES) in chronic non-communicable diseases (NCDs) and offer theoretical evidence for the prevention and control of NCDs.

Design Cross-sectional survey and structural equation modelling.

Setting Nationwide, China.

Participants Female participants in the 2008 National Health Services Survey in China who were 15 years and older.

Results SES factors were associated with the increased risk of NCDs in Chinese women. Education was identified as the most important factor with a protective role (factor loading $=-0.115$ ) for NCDs. Income mainly affected NCDs directly, whereas occupation mainly affected NCDs indirectly. The effects of SES on NCDs were more significant than that of smoking. Medical insurance, smoking and self-reported health played a mediating role in the correlations between those SES factors and NCDs. Conclusions In China, socioeconomic disparities associated with the prevalence of NCDs exist among women. Educational and social interventions are needed to mitigate their negative consequences on health outcomes in Chinese women.

\section{BACKGROUND}

Chronic non-communicable diseases (NCDs) are the leading cause of death worldwide, ${ }^{12}$ and most patients with NCDs live in low/middle-income countries (LMICs). ${ }^{3}$ A study of 23 LMICs revealed that NCDs accounted for $50 \%$ of the total disease burden and approximately $80 \%$ of mortality in $2005 .{ }^{4}$ Unfortunately, the growing threat of NCDs on social and economic development is often underappreciated in LMICs. ${ }^{3}$ Empirical evidence shows that high socioeconomic status (SES) is inversely correlated with NCDs in industrialised Western countries. ${ }^{5}$ However, some studies failed to replicate such findings in developing or transitional countries. $^{6}$
Strengths and limitations of this study

- We used structural equation modelling (SEM) in data analysis which is a powerful tool for developing complex and sophisticated theoretical models that involve a large number of linear equations. SEM can enhance our understanding of the relationships between multiple factors, such as the relative contributions of SES factors and other factors related to non-communicable diseases and the correlations between socioeconomic status and other factors.

- Like all statistical models, SEM presents approximations of reality. Variables included in the SEM models are subject to the restrictions of data availability. Further studies with additional variables may help improve the model fit with reality.

- The National Health Services Survey is a crosssectional survey, which prevents us from making any causal conclusions in the present study.

The mechanism underlying the role of SES in NCDs is largely unknown. Several SES factors, such as income, education and occupation, probably affect NCDs. ${ }^{7}$ Medical insurance is also widely considered as one of the SES indicators, ${ }^{8}$ which may be associated with NCDs. ${ }^{9}$ Many lifestyle and behavioural risk factors are associated with $\mathrm{NCDs}^{10-12}$ and are closely linked to SES. ${ }^{13}$ Lifestyle and behavioural factors have been found to mediate the relationship between SES and self-rated health, ${ }^{14}$ which is a strong predictor of NCDs and mortality with SES gradient. ${ }^{15} 16$ Self-rated health is negatively associated with depressed mood, which may affect physical health problems, particularly NCDs. ${ }^{17}$ The WHO Commission on Social Determinants of Health $^{13}$ considers SES as a structural driver impact on people's daily lives and activities, which in turn influence people's health and well-being.

Previous studies have often failed to delineate the indirect effects of SES. A few studies 
used an SES index to incorporate several indicators. ${ }^{18}$ Other studies selected a single SES indicator. ${ }^{19} 20$ The former approach prevented researchers from further exploring the indirect effects of SES, while the latter skewed the conclusions. Studies using multiple SES indicators have also been reported. ${ }^{21}{ }^{22}$ However, each SES indicator was usually treated as an independent entity.

This study adopted a structural equation modelling (SEM) approach to investigate the associations of SES factors with NCDs, which enabled us to explore associations between multiple variables, as well as the role of a single variable on multiple parameters. Such a study has policy implications for the development of NCDs treatment and intervention programmes because it can improve our understanding of the impact of SES on NCDs.

\section{METHODS}

\section{Study design}

Data used for this study were derived from the 2008 National Health Services Survey (NHSS), which was a nationwide cross-sectional survey organised by the Ministry of Health, China.

\section{Participants and sampling methods}

The participants of this study were restricted to the female participants of the 2008 NHSS in China who were aged 15 years and older.

The NHSS participants were selected using a multistage stratified random sampling strategy. First, 90 cities/ counties were proportionately and randomly selected and classified into five groups based on 10 socioeconomic indicators. Second, five districts/townships were randomly selected from each of these cities/counties. In the third stage, the participating communities were narrowed down to two neighbourhoods/villages randomly from each district/township of the selected cities/counties. Finally, 60 households were randomly selected from each selected community. The health status of the members of the selected households was recorded in a questionnaire. A total of 66500 women met the eligibility criteria of this study. The representativeness and quality of data collected in the NHSS were assessed by the National Health Statistical Center. A Myer's index of 3.48 was found, showing no age bias.

\section{Variables}

Two health outcomes $(\mathrm{Y})$ were calculated in the development of the SEM.

- Number of NCDs: NCDs were defined as a chronic medical condition diagnosed by a physician at least 6 months before the survey. Participants were first asked whether they had experienced one or more NCDs over the past 6 months. If the answer was 'yes', the specific diagnoses were recorded. The main NCDs reported by the participants included cancer, heart disease, cerebrovascular disease, respiratory disease, endocrine disorders and nutrition and metabolic disease.

- Self-reported health: This was measured using a health rating scale ranging from 0 (worst) to 100 (best).

The following SES indicators were collected in the 2008 NHSS:

- Educational attainment was measured by years of study based on a scale of 1 to 4 , with 1 indicating no formal education, 2 indicating education up to middle school, 3 indicating high school level and 4 indicating college and university-level education.

- Individual annual income was classified into five groups: 1 (s2500yuan), 2 (2501-3999 yuan), 3 (4000-5999 yuan), 4 (6000-10 000 yuan) and 5 (>10000 yuan).

- Occupation was classified into five groups: 1 (no paid job), 2 (manual, such as farming), 3 (semimanual), 4 (skilled) and 5 (management).

- Medical insurance was coded according to the level of security covered by the government-sponsored social health insurance schemes: 1, no insurance coverage; 2, New Rural Cooperative Medical Scheme (NCMS) and Medical Insurance for Urban Residents (MIUR); and 3, Medical Insurance for Urban Employees (MIUE) and Free Medical Care (FMC).

Behavioural risk factors of NCDs measured in the 2008 NHSS included smoking, alcohol consumption, physical activity and preventive medical examination. However, only smoking and physical activity were found to be associated with NCDs. The association between physical activity and NCDs was not linear: moderate physical exercise reduced NCDs, whereas vigorous exercise increased NCDs. Therefore, only smoking was incorporated in the SEM. We tested four measures of smoking in the SEM: smoking as a dichotomous variable (yes or no), frequency of smoking, volume of cigarette consumption and a latent variable incorporating both frequency and volume of cigarette consumption. The dichotomous measurement of smoking produced the best fit of the model.

\section{Data collection}

A questionnaire survey was undertaken through faceto-face interviews, with a response rate of $83 \%$. When a household member was absent, a proxy respondent was considered. In total, $<30 \%$ of questionnaires were completed by proxy respondents.

The interviews were conducted by community health workers with supervision from medical doctors. Training was provided to all of the interviewers and supervisors prior to the survey. Each supervisor was required to visit $5 \%$ of the households under his/her supervision to examine the accuracy of the data recorded in the questionnaires. Fourteen questions were repeated during the supervisor visits in the absence of the interviewers. A consistency rate of $91-97 \%$ was recorded. 


\section{Data analysis}

We used SPSS (V.16) for the descriptive and regression (linear and logistic) analyses and AMOS 17 for SEM. We transformed the NCDs variable into dichotomous (yes $=1$, no $=0$ ) and performed logistic regression analyses to explore its associations with various SES and behavioural variables (including interactions between some of those variables). We also performed linear regression analyses considering the number of NCDs conditions as a continuous measurement. The major findings are consistent with the SEM results. To simplify reporting, this article only presents the SEM results. Details about the regression analyses can be found in the online supplementary materials.

The SEM analyses were performed to test the relationships between health outcomes, SES and behavioural risk factors. SEM is a statistical method that takes a confirmatory approach to the analysis of a structural theory. ${ }^{23}$ It allows analyses of multiple independent variables and multiple dependent variables in one model. ${ }^{24}$ SEM has been widely applied in studies related to social psychology and behavioural medicine. It has also been increasingly used in NCDs studies, including identification of effective interventions designed to improve the lives of individuals with disabilities and chronic illness. ${ }^{25-27}$ This study contained two health outcomes (dependent variables) and multiple independent variables (SES and behavioural factors). The SEM approach scored over the traditional regression method.

In this study, SES was measured by education, individual annual income, occupation and medical insurance. We constructed a latent variable incorporating all of the above SES indicators first. But the results of goodness-of-fit test for the SEM were not acceptable, simply because the directions of impact of the SES indicators on NCDs were different: some were protective factors but others were risk factors. Moreover, these SES indicators influenced each other. Therefore, we used path analysis with observed variables to construct the SEM in which only observed variables were contained. We tested the significance of each factor on NCDs by bootstrap (the number of bootstrap samples was 5000) and analysed their effects on NCDs. The robustness of the SEM models was confirmed by logistic regression and linear regression analyses (results are supplied in the online supplementary materials

Five SEM models were developed to test the hypotheses, all including education, individual annual income, occupation, medical insurance, smoking, self-reported health and NCDs. Figure 1 depicts the base model. Model A added education $\rightarrow$ individual annual income on the basis of the base model. Model B introduced individual annual income $\rightarrow$ medical insurance based on model A. Model $\mathrm{C}$ added education $\rightarrow$ smoking on the basis of model $\mathrm{B}$. Finally, model D introduced individual annual income $\rightarrow-$ smoking on the basis of model C.

Goodness-of-fit testing provided additional evidence to support the mediation hypotheses. We evaluated the SEM using a number of model fit indices. A non-significant $\chi^{2}$ indicates a good fit. We also examined the goodness-of-fit

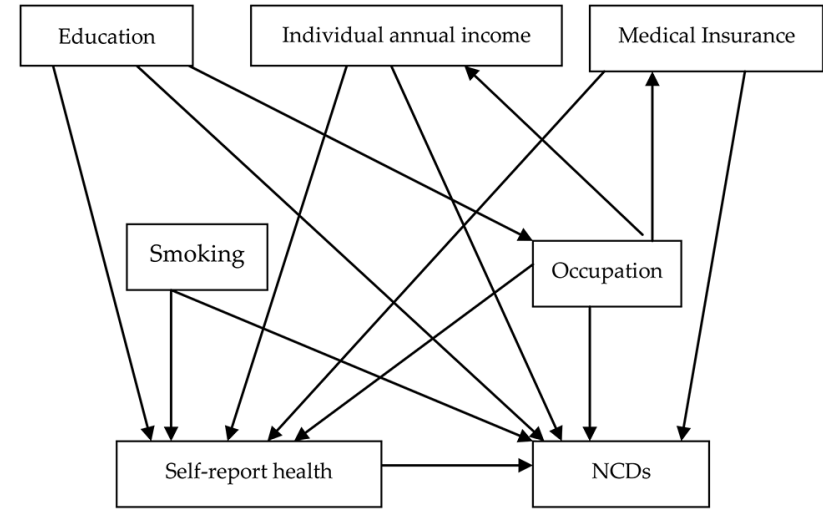

Figure 1 Base structural equation modelling model. This is the base model describing the complex relationships between all variables. Here, ' $\mathrm{X} \rightarrow \mathrm{Y}$ ' means $\mathrm{X}$ influenced Y. NCDs, non-communicable diseases.

index (GFI) and the adjusted goodness-of-fit index (AGFI), root mean square error of approximation (RMSEA) and root mean square residual (RMR). These indices ranged from 0 to 1 , with a value $\geq 0.90$ for GFI and AGFI, $\leq 0.06$ for RMSEA and $\leq 0.08$ for RMR indicating a good fit of models.

\section{RESULTS}

\section{Participant profile}

The majority ( $73 \%$ ) of participants had completed middle or high school education. Their personal income was distributed evenly across the five ranges. More than $50 \%$ of all the participants engaged in manual labour. The low entitlement insurance schemes (NCMS/MIUR) covered $>70 \%$ of participants. Less than $3 \%$ of participants were smoking at the time of the survey (table 1).

\section{NCDs and SES, self-reported health}

Nearly $2.98 \%$ of participants suffered from two NCDs, while $0.7 \%$ suffered from three or more NCDs. The participants reported an average score of $80.02(\mathrm{SD}=14.23)$ out of 100 for perceived overall health.

Education, individual annual income, occupation, medical insurance and smoking were associated with NCDs (table 1). Higher educational attainment, lower income and absence of smoking were associated with lower prevalence of NCDs $(p<0.0001)$.

A gradient relationship between self-reported health and NCDs conditions was found: best perceived health in those without NCDs $(82.70 \pm 12.36)$, intermediate health score in those with one NCD $(68.88 \pm 15.19)$ and worst perceived health in those with two $(62.98 \pm 15.73)$ and three or more

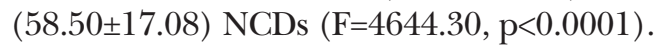

\section{Model fit}

The base model showed poor model fit, with $\chi^{2}$ statistics, RMR and RMSEA failing to reach the cut-off criteria. The model fit improved with the addition of mediators. Model D, incorporating all the three mediator hypotheses, produced the best fit (table 2). 
Table 1 Socioeconomic status and prevalence of non-communicable diseases (NCDs)

\begin{tabular}{|c|c|c|c|c|c|c|}
\hline \multirow{2}{*}{$\begin{array}{l}\text { Characteristics of } \\
\text { participants }\end{array}$} & \multirow[b]{2}{*}{ N (\%) } & \multicolumn{4}{|l|}{ NCDs, n (\%) } & \multirow[b]{2}{*}{ p Value } \\
\hline & & 0 & 1 & 2 & 3 & \\
\hline Education & & & & & & $<0.001$ \\
\hline 1. No formal education & $13836(20.81)$ & $9736(70.37)$ & $3248(23.47)$ & $703(5.08)$ & $149(1.08)$ & \\
\hline 2. Up to middle school & 39027 (58.69) & 32927 (84.37) & $4884(12.51)$ & $983(2.52)$ & $233(0.60)$ & \\
\hline 3. Up to high school & 9756 (14.67) & $8595(88.10)$ & $879(9.01)$ & $223(2.29)$ & $59(0.60)$ & \\
\hline 4. College/university & $3881(5.84)$ & $3535(91.08)$ & $254(6.54)$ & $70(1.80)$ & $22(0.57)$ & \\
\hline Individual annual income & & & & & & $<0.001$ \\
\hline 1. $\sim 2500$ & $14515(21.83)$ & $12186(83.95)$ & 1935 (13.33) & $326(2.25)$ & $68(0.47)$ & \\
\hline 2. $\sim 4000$ & $13519(20.33)$ & $11388(84.24)$ & $1771(13.10)$ & $308(2.28)$ & $52(0.38)$ & \\
\hline 3. $\sim 6000$ & $12328(18.54)$ & $10332(83.81)$ & 1609 (13.05) & $325(2.64)$ & $62(0.50)$ & \\
\hline 4. $\sim 10000$ & $14052(21.13)$ & $11653(82.93)$ & $1883(13.40)$ & $423(3.01)$ & $93(0.66)$ & \\
\hline 5. $>10000$ & $12086(18.17)$ & $9234(76.40)$ & $2067(17.10)$ & $597(4.94)$ & $188(1.56)$ & \\
\hline Occupation & & & & & & $<0.001$ \\
\hline 1. No paid job & 17969 (27.02) & 14437 (80.34) & 2753 (15.32) & $642(3.57)$ & $137(0.76)$ & \\
\hline 2. Manual (farmer) & $34310(51.59)$ & 29413 (85.73) & $4176(12.17)$ & $617(1.80)$ & $104(0.30)$ & \\
\hline 3. Semimanual & $7062(10.62)$ & $5524(78.22)$ & $1104(15.63)$ & $333(4.72)$ & $101(1.43)$ & \\
\hline 4. Skilled & $4634(6.97)$ & 3549 (76.59) & 770 (16.62) & $239(5.16)$ & $76(1.64)$ & \\
\hline 5. Management & $2525(3.80)$ & $1870(74.06)$ & $462(18.30)$ & $148(5.86)$ & $45(1.78)$ & \\
\hline Medical insurance & & & & & & $<0.001$ \\
\hline 1. No insurance & 8704 (13.09) & $7440(85.48)$ & 1020 (11.72) & $194(2.23)$ & $50(0.57)$ & \\
\hline 2. NCMS/MIUR & $47232(71.03)$ & $39698(84.05)$ & $6212(13.15)$ & $1120(2.37)$ & $202(0.43)$ & \\
\hline 3. MIUE/FMC & $10564(15.89)$ & $7655(72.46)$ & $2033(19.24)$ & $665(6.29)$ & $211(2.00)$ & \\
\hline Smoking & & & & & & $<0.001$ \\
\hline 1. No & 64801 (97.45) & $53596(82.71)$ & 8892 (13.72) & $1875(2.89)$ & $438(0.68)$ & \\
\hline 2. Yes & $1699(2.55)$ & $1197(70.45)$ & $373(21.95)$ & $104(6.12)$ & $25(1.47)$ & \\
\hline
\end{tabular}

All $p$ values were two-tailed.

FMC, Free Medical Care; MIUE, Medical Insurance for Urban Employees; MIUR, Medical Insurance for Urban Residents; NCMS, New Rural Cooperative Medical Scheme.

\section{Estimates of regression weights in model D}

Model D (figure 2) was the only tested model that met all of the model fit criteria including the $\chi^{2}$ statistics. It showed that higher educational attainment and self-reported health were protective factors for NCDs. Smoking, higher income, occupations with less manual labour and higher levels of medical insurance entitlement were risk factors for NCDs. Self-reported health was positively associated with higher educational attainment and higher income, and negatively associated with smoking, occupations with less manual labour and higher levels of medical insurance entitlement (figure 2).

Model D confirmed the significant correlation between smoking and SES, and between SES indicators. Smoking was negatively correlated with educational attainment

\begin{tabular}{|c|c|c|c|c|c|c|c|}
\hline Model & $\chi^{2}$ & df & p Value & RMR & GFI & AGFI & RMSEA \\
\hline Base model & 5112.503 & 7 & $<0.001$ & 0.220 & 0.979 & 0.916 & 0.105 \\
\hline Model A & 1214.684 & 6 & $<0.001$ & 0.043 & 0.995 & 0.976 & 0.055 \\
\hline Model B & 330.820 & 5 & $<0.001$ & 0.069 & 0.999 & 0.992 & 0.031 \\
\hline Model C & 47.797 & 4 & $<0.001$ & 0.006 & 1.000 & 0.999 & 0.013 \\
\hline Model D & 0.774 & 3 & 0.856 & 0.002 & 1.000 & 1.000 & 0.000 \\
\hline
\end{tabular}

All $p$ values were two-tailed.

AGFI, adjusted goodness-of-fit index; GFI, goodness-of-fit index; RMR, root mean square residual; RMSEA, root mean square error of approximation. 


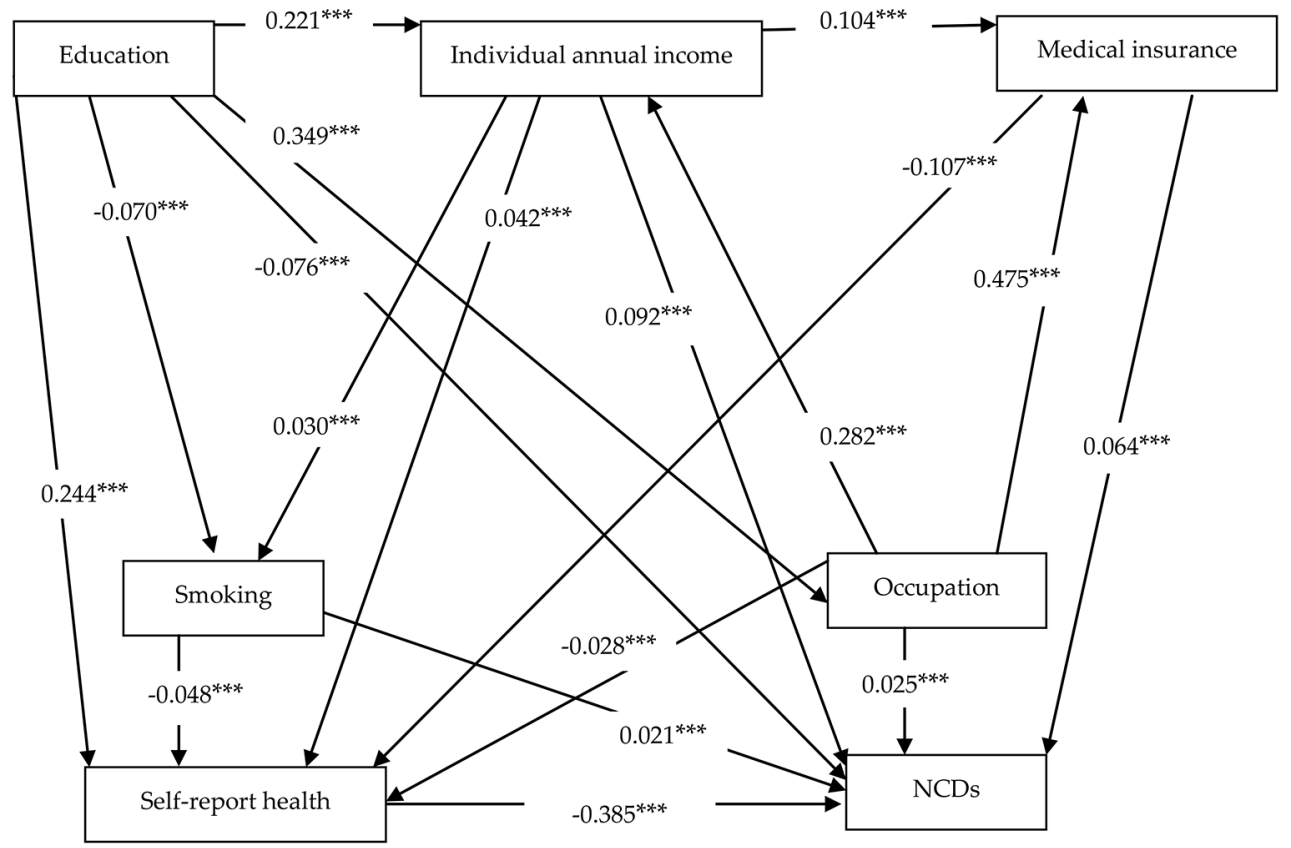

Figure 2 Structural equation modelling (SEM) model D. This is the SEM model D with best fit, which describes the mechanisms involved in the relationships between SES and non-communicable diseases (NCDs) including their direction and size. ' $X \rightarrow Y$ ' means $X$ influenced $Y$. The numbers above the ' $\rightarrow$ ' are standardised regression weights. ${ }^{\star \star *} p<0.001$ (two-tailed test).

and positively correlated with income levels. The income of the participants increased with higher educational attainments. Higher income was also correlated with higher levels of medical insurance entitlement $(\mathrm{p}<0.001$; figure 2).

\section{Estimates of direct and indirect effects}

Overall, self-reported health had the greatest total effect on NCDs $\left(r^{\prime}=-0.385\right)$, followed by education $\left(r^{\prime}=-0.115\right)$. Education and medical insurance affected NCDs both directly and indirectly (table 3 ). The direct effect of income on NCDs was much greater than its indirect effect. The likelihood of income influencing NCDs via mediators (such as medical insurance and smoking) was minimal because its indirect effect was close to zero (table 3). The indirect effect of occupation on NCDs was greater than its direct effect. A partial mediator effect was confirmed, which suggested that occupation affected

\begin{tabular}{|c|c|c|c|}
\hline & Total & Direct & Indirect \\
\hline Individual annual income & $0.088^{* * *}$ & $0.092^{\star \star *}$ & $-0.004^{*}$ \\
\hline Occupation & $0.110^{\star \star \star}$ & $0.025^{\star \star \star}$ & $0.086^{\star \star \star}$ \\
\hline Medical insurance & $0.105^{\star \star \star}$ & $0.064^{\star \star \star}$ & $0.041^{\star \star \star}$ \\
\hline Education & $-0.115^{\star \star \star}$ & $-0.076^{\star \star \star}$ & $-0.039^{\star \star \star}$ \\
\hline Smoking & $0.040^{\star \star \star}$ & $0.021^{\star \star \star}$ & $0.018^{\star \star \star}$ \\
\hline Self-reported health & $-0.385^{\star \star \star}$ & $-0.385^{\star \star *}$ & 0.000 \\
\hline
\end{tabular}

All the effects were standardised.

${ }^{*} \mathrm{p}<0.05$ (two-tailed test); ${ }^{* * *} \mathrm{p}<0.001$ (two-tailed test); '0' indicates that self-reported health did not affect NCDs indirectly.
NCDs mainly through mediators such as income and medical insurance (table 3). Smoking had a weak effect on NCDs compared with the SES factors (table 3).

\section{DISCUSSION}

Chinese women are exposed to high levels of SES risk factors for NCDs. This study identified low levels of education, higher income and occupations with less manual labour as major predictors of NCDs. Meanwhile, medical insurance, smoking and self-reported health played a mediating role in the correlations between those SES factors and NCDs.

One of the strengths of this study is that we used SEM in data analysis which is a powerful tool for developing complex and sophisticated theoretical models that involve a large number of linear equations. SEM can enhance our understanding of the relationships between multiple factors, such as the relative contributions of SES factors and other factors related to NCDs and the correlations between SES and other factors. Furthermore, data of this study were drawn from a nationwide household survey, one of the largest and most representative data sets currently available in China. However, like all statistical models, SEM presents approximations of reality. The NHSS is a cross-sectional survey, which prevents us from making any causal conclusions in the present study.

Unlike most previous studies which examined the relationships between SES and NCDs in high-income countries, this study expands our understanding of such relationships to the contexts of developing and transitional economies. Over the past decades, China experienced rapid economic growth, but with 
enormous wealth inequalities. NCDs have started to attract increasing concerns ${ }^{28} 29$ as they account for an estimated $80 \%$ of deaths and $70 \%$ of disability-adjusted life-years lost in China. ${ }^{30}$ But there is paucity in studies focusing on Chinese women. Chinese women are more vulnerable to NCDs than men. With the founding of the People's Republic of China, the social status of Chinese women improved under the leadership of Chairman Mao, who advocated gender equality. However, increased workforce participation does not exempt women from their traditional household duties, which leads to serious problems in work-life balance. ${ }^{31}$ The 2008 NHSS in China revealed a higher prevalence of many NCDs in Chinese women compared with Chinese men. ${ }^{32}$ In addition, the association between SES and NCDs is gender-dependent. For example, hypertension was found to be inversely associated with SES in women, but positively associated with SES in men. ${ }^{20}{ }^{21}$ Moreover, women are more likely to experience socioeconomic difficulties than their male counterparts. $^{33}$

This study found that education is the most important SES determinant of NCDs for Chinese women. Education has been widely accepted as a protective SES factor for NCDs ${ }^{34-38}$ The $2002-2004$ World Health Survey (WHS) reported that education was inversely correlated with chronic diseases except for diabetes in LMICs. ${ }^{37}$ Cois $e t$ al discovered that higher education predicts lower prevalence of hypertension in South Africa. ${ }^{27}$ The WHO also reported a link between higher education and lower prevalence of NCDs in China. ${ }^{38}$ We found that the effects of education on NCDs involved both direct and indirect effects, and they were mediated by smoking and other SES factors. Indeed, education is a strong predictor of smoking incidence. ${ }^{39}$ Educational disparities exist among Chinese women due to unbalanced socioeconomic development, such as those between urban and rural communities. The results of the 2010 population census of China showed that the illiteracy rate of urban women aged 15 years and above was $3.03 \%$, but the illiteracy rate of those living in rural towns and counties was $5.90 \%$ and $10.66 \%$, respectively. ${ }^{40}$

In this study, we found that women with higher incomes are more likely to suffer from NCDs, similar to findings from other studies in China ${ }^{38}$ and other LMICs. ${ }^{41}$ However, several studies reached a different conclusion: Cois $e t$ al found that higher income predicts lower blood pressure in South Africa ${ }^{27}$; the 2002-2004 WHS revealed a positive correlation between wealth and NCDs only for diabetes in LMICs. ${ }^{37}$ It is important to acknowledge that women in China have been encouraged to participate in the workforce. Despite their increased income, women are still under great pressure to fulfil their traditional duties in the family. The dual pressure (social and family) renders working women more vulnerable to health problems than men. ${ }^{32} 334243$ Meanwhile, higher income has increased the adoption of sedentary lifestyles and excessive calorie intake, imposing a higher risk of NCDs. According to the Chinese National Nutrition and Health
Survey in 2002, nearly 300 million Chinese people were overweight or obese. Around $18.6 \%$ of Chinese adults manifested abnormal blood lipids. ${ }^{44}$

We found that higher levels of medical insurance entitlement are associated with a higher risk of NCDs. This result is consistent with findings of a survey in six middle-income countries including China, which reported a higher prevalence of hypertension in people with mandatory medical insurance compared with those without insurance. ${ }^{45}$ However, another study in LMICs revealed a negative association between medical insurance and depression. ${ }^{46}$ Medical insurance may influence health through various channels. A lack of medical insurance limits access to preventive services. ${ }^{47}$ In China, individuals are not entitled to select from the different insurance schemes available. ${ }^{32}$ Social health insurance schemes in China are tied to residency and occupation. The association between medical insurance and NCDs partially reflects occupational and urban-rural disparities. We cannot exclude the possibility of reporting bias either. In this study, NCDs were defined as a diagnostic condition. FMC/MIUE enrollees are more likely to visit doctors and seek hospital services than NCMS/MIUR enrollees. ${ }^{32}$ Therefore, they may be more likely to report NCDs.

The link between manual labour and lower risk of NCDs demonstrated in this study is consistent with other studies. A systematic review and meta-analysis concluded that farmers and manual labourers have lower risk of hypertension than other workers. ${ }^{48}$ This may reflect higher levels of physical activities in these labourers. ${ }^{48}$ Occupations with limited manual labour are associated with additional NCDs risks. A study conducted in Beijing found that $65.4 \%$ of urban employees frequently worked overtime; $47.1 \%$ felt 'overloaded' and 29\% felt 'exhausted' ${ }^{50}$ The 'White Book on Urban White-collar Health in China' released by Chinese medical professional bodies in 2010 reported that $76 \%$ of urban white-collar workers were in a subclinical health condition, with nearly 6 in 10 complaining of fatigue. Clearly, higher income and medical insurance entitlement does not improve individual health automatically. Instead, their NCDs conditions may have been further exacerbated by higher income and medical insurance entitlement. Indeed, we found that the effect of occupation on NCDs is partially mediated by income and medical insurance.

Surprisingly, smoking appeared to be a weak predictor of NCDs in this study, probably due to the low smoking rate $(2.55 \%)$ among the participants and the high level $(72.4 \%)$ of exposure to passive smoking. ${ }^{51}$ Nonetheless, smoking remains one of the top five risk factors threatening women's health in China. China is the world's largest tobacco producer and consumer. The total number of adult smokers in China has exceeded 300 million, including 10 million women. Furthermore, tobacco control is a huge challenge, ${ }^{52}$ especially when smoking is combined with socioeconomic factors. ${ }^{53}$ Our SEM results demonstrated a positive association between 
smoking and income and a negative association between smoking and education. A survey in 48 LMICs showed that wealth is not associated with smoking in Chinese women although this is not the case in 19 countries where richer women are more likely to smoke than the poor. ${ }^{54}$ Given the financial sensitivity of tobacco consumption, the tobacco levy introduced in China recently may become an effective instrument for tobacco control.

Self-reported health played an important role in the SEM model, the effect of self-reported health on NCDs is profound $\left(r^{\prime}=-0.385\right)$. Self-reported health is also closely associated with SES and plays a mediating role. These findings are consistent with studies undertaken elsewhere. ${ }^{55-58}$ A study in East Asia reported a positive association between income and self-reported health in Chinese women, but failed to establish an association between occupation and self-reported health in those women. ${ }^{55} \mathrm{~A}$ few researchers believe that self-reported health reflects physiological, mental and social indices. ${ }^{59}$ Empirical evidence suggests that self-reported health is a reliable predictor of morbidity and mortality. ${ }^{160}$

In conclusion, China is facing a serious challenge during the current socioeconomic transition. A complex network of risk factors is associated with NCDs. Socioeconomic disparities associated with the prevalence of NCDs exist among women in China. High educational attainment is associated with a low risk of NCDs. However, the robust economic development has failed to translate into reduced risks of NCDs. Like the cases in many developing countries, high income is associated with an increased risk of NCDs, as well as increased smoking rate. The effect of occupation on NCDs is also mediated by income and economic development. People engaged in less manual labour are more likely to live in urban areas, earn a high income and enjoy high levels of entitlement with medical insurance, which in turn increases their risks of NCDs.

The findings of this study have policy implications for establishing responsive intervention strategies targeting NCDs in developing economies. Economic development in many developing countries, such as China, has been accompanied by many social challenges, including the increasing burden of NCDs. It is important to note that women are likely to suffer disproportional risks of NCDs due to gender inequalities in SES. Education may hold the key to mitigating such negative consequences. However, generalisation of the findings to other countries needs to be cautious because the SES of women varies across countries. The SES risk factors for NCDs may be context-dependent.

There were several limitations in this study. The status of NCDs was self-reported, and therefore, the findings are subject to recall bias. Although the major findings of the SEM were confirmed by the results of regression analyses, several interaction effects failed to achieve statistical significance in the regression analyses. Finally, the study focused on Chinese women, which did not illustrate the situation of NCDs for the entire Chinese population. Further studies are needed to answer the following questions: (1) Are there differences between men and women in relation to SES risk factors for NCDs? (2) What are the underlining reasons for the gender differences in SES risk factors for NCDs? (3) What difference (effect size) will education make to reduce gender inequalities in NCDs?

Acknowledgements The authors appreciate two reviewers of this article for their very constructive comments and suggestions. Ms Michele Mooney provided editing and proofreading services.

Contributors QW had full access to all the study data and is responsible for the integrity of the data and the accuracy of data analysis. Study concept and design: QW, YH, LW, LL; acquisition, analysis, or interpretation of data: HY, YC, YT; draft of the manuscript: $\mathrm{HY}$; critical revision of the manuscript for important intellectual content: HY, YC, QW, YH, CL; statistical analysis: HY, YC, YL, LL.

Funding National Natural Science Fund (grant numbers 71403074 and 71333003 ). Competing interests None declared.

Patient consent Obtained.

Ethics approval The research was approved by the Medical Ethics Committee of Harbin Medical University (Daqing).

Provenance and peer review Not commissioned; externally peer reviewed. Data sharing statement There are not additional unpublished data from this study.

Open Access This is an Open Access article distributed in accordance with the Creative Commons Attribution Non Commercial (CC BY-NC 4.0) license, which permits others to distribute, remix, adapt, build upon this work non-commercially, and license their derivative works on different terms, provided the original work is properly cited and the use is non-commercial. See: http://creativecommons.org/ licenses/by-nc/4.0/

(c) Article author(s) (or their employer(s) unless otherwise stated in the text of the article) 2017. All rights reserved. No commercial use is permitted unless otherwise expressly granted.

\section{REFERENCES}

1. World Health Organization. Global status report on noncommunicable diseases 2010, 2011.

2. World Health Organization. The global burden of disease: 2004 update, 2008.

3. World Health Organization. Preventing chronic diseases: a vital investment: WHO global report, 2005.

4. Abegunde DO, Mathers CD, Adam T, et al. The burden and costs of chronic diseases in low-income and middle-income countries. Lancet 2007;370:1929-38.

5. World Health Organization. Noncommunicable diseases country profiles, 2014.

6. Song YM, Ferrer RL, Cho SI, et al. Socioeconomic status and cardiovascular disease among men: the Korean national health service prospective cohort study. Am J Public Health 2006;96:152-9.

7. Adler NE, Ostrove JM. Socioeconomic status and health: what we know and what we don't. Ann N Y Acad Sci 1999;896:3-15.

8. Smith DF, Ishman SL, Tunkel DE, et al. Chronic rhinosinusitis in children: race and socioeconomic status. Otolaryngol Head Neck Surg 2013;149:639-44.

9. Ward BW, Schiller JS, Goodman RA. Multiple chronic conditions among US adults: a 2012 update. Prev Chronic Dis 2014;11:E62.

10. Xq Q, Wang Y. Report on chronic disease in China. Chinese Beijing: Center for Disease Control and Prevention, 2006.

11. Wen W, Shu XO, Gao YT, et al. Environmental tobacco smoke and mortality in Chinese women who have never smoked: prospective cohort study. BMJ 2006;333:376.

12. Stallones RA. The association between tobacco smoking and coronary heart disease. Int J Epidemiol 2015;44:735-43.

13. World Health Organization. Closing the gap in a generation: health equity through action on the social determinants of health: final report of the commission on social determinants of health, 2009.

14. Kim J. The mediating effects of lifestyle factors on the relationship between socioeconomic status and self-rated health among middle-aged and older Adults in Korea. Int J Aging Hum Dev 2011;73:153-73. 
15. Burström B, Fredlund P. Self rated health: is it as good a predictor of subsequent mortality among adults in lower as well as in higher social classes? J Epidemiol Community Health 2001;55:836-40.

16. Reyes Fernández B, Rosero-Bixby L, Koivumaa-Honkanen H. Effects of self-rated health and self-rated economic situation on depressed mood via life satisfaction among older adults in Costa Rica. J Aging Health 2016;28:225-43.

17. Guthrie EA, Dickens C, Blakemore A, et al. Depression predicts future emergency hospital admissions in primary care patients with chronic physical illness. J Psychosom Res 2016;82:54-61.

18. Mulatu MS, Schooler C. Causal connections between socioeconomic status and health: reciprocal effects and mediating mechanisms. J Health Soc Behav 2002;43:22-41.

19. Walsemann KM, Gee GC, Ro A. Educational attainment in the context of social inequality: new directions for research on education and health. Am Behav Sci 2013;57:1082-104.

20. Goldstein J, Jacoby E, del Aguila R, et al. Poverty is a predictor of non-communicable disease among adults in Peruvian cities. Prev Med 2005;41:800-6.

21. Fleischer NL, Diez Roux AV, Alazraqui M, et al. Social patterning of chronic disease risk factors in a Latin American city. J Urban Health 2008;85:923-37.

22. Kivimäki M, Lawlor DA, Davey Smith G, et al. Socioeconomic position, co-occurrence of behavior-related risk factors, and coronary heart disease: the finnish public sector study. Am J Public Health 2007:97:874-9.

23. Byrne BM. Structural equation modeling with mplus: basic concepts, applications, and programming. New York: Routledge, 2011.

24. Merchant WR, Li J, Karpinski AC, et al. A conceptual overview of structural equation modeling (SEM) in rehabilitation research. Work 2013:45:407-15.

25. Weston R, Gore PA, Chan F, et al. An introduction to using structural equation models in rehabilitation psychology. Rehabil Psychol 2008;53:340-56.

26. Kim JN, Lee S. Communication and cybercoping: coping with chronic illness through communicative action in online support networks. J Health Commun 2014;19:775-94.

27. Cois A, Ehrlich R. Analysing the socioeconomic determinants of hypertension in South Africa: a structural equation modelling approach. BMC Public Health 2014;14:414.

28. Boutayeb A, Boutayeb S. The burden of non communicable diseases in developing countries. Int J Equity Health 2005:4:2.

29. Chin CY, Pengal S. Cardiovascular disease risk in a semirural community in Malaysia. Asia Pac J Public Health 2009;21:410-20.

30. Wang L, Kong L, Wu F, et al. Preventing chronic diseases in China. Lancet 2005;366:1821-4.

31. Feng Y. Study on the relationship between professional women's role orientation, work-family conflict and work-life quality. Master, Zhejiang University 2004.

32. An analysis Report of National Health Services survey in China, 2008. Beijing: Peking: Union Medical College Press, 2009.

33. Launch of the report on women and health: today's evidence tomorrow's agenda. http://www.who.int/dg/speeches/2009/women health_report_20091109/en/ (accessed on 9 Nov 2009).

34. Eide ER, Showalter MH. Estimating the relation between health and education: what do we know and what do we need to know? Econ Educ Rev 2011;30:778-91.

35. Elo IT. Social Class Differentials in Health and Mortality: patterns and explanations in Comparative Perspective. Annu Rev Sociol 2009;35:553-72.

36. Kawachi I, Adler NE, Dow WH. Money, schooling, and health: mechanisms and causal evidence. Ann N Y Acad Sci 2010;1186:56-68.

37. Hosseinpoor AR, Bergen N, Mendis S, et al. Socioeconomic inequality in the prevalence of noncommunicable diseases in lowand middle-income countries: results from the World Health Survey. BMC Public Health 2012;12:474.

38. Bauman A, Phongsavan P, Schoeppe S, et al; Noncommunicable disease risk factors and socioeconomic inequalities-what are the links? A multicountry analysis of noncommunicable disease surveillance data. Report to the WHO Regional Office for the Western Pacific. Geneva: World Health Organization, 2010.
39. Kimbro RT, Bzostek S, Goldman N, et al. Race, ethnicity, and the education gradient in health. Health Aff 2008;27:361-72.

40. Population Census office under the State Council, Department of Population and Employment Statistics National Bureau of Statistics of China. tabulation on the 2010 population census of the people's Republic of China. Beijing: China Statistics Press, 2012.

41. Chang CL, Marmot MG, Farley TM, et al. The influence of economic development on the association between education and the risk of acute myocardial infarction and stroke. J Clin Epidemiol 2002;55:741-7.

42. Ali BS, Rahbar MH, Naeem S, et al. Prevalence of and factors associated with anxiety and depression among women in a lower middle class semi-urban community of Karachi, Pakistan. J Pak Med Assoc 2002;52:513-7.

43. Shang L, Liu P, Fan LB, et al. Impact of work and family stress on health functioning in working women. Chin J Behav Med \& Brain Sci 2009;18:151-3.

44. Lm L, Rao KQ, Kong LZ, et al. The Technical Working Group of China National Nutrition and Health Survey. A description on the Chinese National nutrition and health survey in 2002. Chin J Epidemiol 2005;26:478-84.

45. Basu S, Millett C. Social epidemiology of hypertension in middleincome countries: determinants of prevalence, diagnosis, treatment, and control in the WHO SAGE study. Hypertension 2013;62:18-26.

46. Brinda EM, Rajkumar AP, Attermann J, et al. Health, social, and economic variables associated with depression among older people in low and middle income countries: world health organization study on global AGEing and adult health. Am J Geriatr Psychiatry 2016;24:1196-208

47. Meyer CP, Allard CB, Sammon JD, et al. The impact of medicare eligibility on Cancer screening behaviors. Prev Med 2016;85:47-52.

48. Busingye D, Arabshahi S, Subasinghe AK, et al. Do the socioeconomic and hypertension gradients in rural populations of low- and middle-income countries differ by geographical region? A systematic review and meta-analysis. Int J Epidemiol 2014:43:1563-77.

49. Yang GH, Ma JM, Liu N, et al. [Study on diet, physical activities and body mass index in chinese population in 2002]. Zhonghua Liu Xing Bing Xue Za Zhi 2005;26:246-51.

50. Yang $H Q$, Han FX, Xiao HM. Investigation on overwork of employees in Beijing. Population \& Economics 2009;2:33-41.

51. General Administration of Quality Supervision, Inspection and Quarantine of the People's Republic of China. Tobacco control planning in China (2012-2015, 2012.

52. WHO Report on the global tobacco epidemic, 2013: enforcing bans on tobacco advertising, Promotion and sponsorship: World Health Organization, 2013.

53. Osler M, Holstein B, Avlund K, et al. Socioeconomic position and smoking behaviour in Danish Adults. Scand J Public Health 2001;29:32-9.

54. Hosseinpoor AR, Parker LA, Tursan d'Espaignet E, et al Socioeconomic inequality in smoking in low-income and middleincome countries: results from the World Health Survey. PLoS One 2012;7:e42843.

55. Hanibuchi T, Nakaya T, Murata C. Socio-economic status and selfrated health in East Asia: a comparison of China, Japan, South Korea and Taiwan. Eur J Public Health 2012;22:47-52.

56. Froom P, Melamed S, Triber I, et al. Predicting self-reported health: the CORDIS study. Prev Med 2004;39:419-23.

57. Lindström M, Moghaddassi M, Merlo J. Individual self-reported health, social participation and neighbourhood: a multilevel analysis in Malmö, Sweden. Prev Med 2004;39:135-41.

58. Sacker A, Worts D, McDonough P. Social influences on trajectories of self-rated health: evidence from Britain, Germany, Denmark and the USA. J Epidemiol Community Health 2011;65:130-6.

59. Molarius A, Berglund K, Eriksson C, et al. Socioeconomic conditions, lifestyle factors, and self-rated health among men and women in Sweden. Eur J Public Health 2007:17:125-33.

60. Månsson NO, Råstam L. Self-rated health as a predictor of disability pension and death--a prospective study of middle-aged men. Scand J Public Health 2001;29:151-8. 